\title{
Ortofotolar ile Nesne Tabanlı Görüntü Sınıflandırma Uygulaması: Van- Erciş Depremi Örneği
}

\author{
Aslı Sabuncu ${ }^{1,2, *}$, Filiz Sunar ${ }^{2}$ \\ ${ }^{1}$ Boğaziçi Üniversitesi Kandilli Rasathanesi ve Deprem Araştırma Enstitüsü Jeodezi Anabilim Dalı, 34684, Üsküdar, İstanbul. \\ 2istanbul Teknik Üniversitesi, Geomatik Mühendisliği Bölümü, 34469, Maslak, İstanbul.

\section{Özet}

Depremler, çok fazla sayıda can kayıplarına, alt yapı zararlarına, ciddi maddi kayıplara neden olan en yıkıcı doğal afetlerdir. Deprem nedeni ile yıkılmış binaların deprem sonrası tespiti önemli bir aşamadır çünkü bu tip binalar şehirler için risk oluşturmaktadır. Son yıllarda dijital fotogrametri ve uzaktan algılama teknolojileri ile uydu algılaylcıları/kamera sistemlerindeki önemli gelişmeler yeni ve farklı araştırma konu ve uygulamalarının ortaya çıkmasına neden olmuştur. 1950'li yıllardan bu yana gelişim gösteren dijital kamera teknolojisi beraberinde yüksek mekansal çözünürlük ve konumsal doğruluğa sahip ortofotoların üretimi de olanaklı hale gelmistir. Bu ortofotolar detay çıkartımında ve tematik sınıflandırmada başarı ile kullanılmaktadır. Yüksek mekansal çözünürlüğe bağll olarak tematik sinıflandırmada geleneksel piksel tabanlı sınıflandırma yaklaşımı yerine nesne tabanlı yaklaşım önem kazanmış ve yaygınlaşmıştır. Bu çalışma için Türkiye'nin doğusunda yer alan Van ili-Erciş ilçesi seçilmiştir. Bölgede, 23 Ekim 2011 tarihinde yerel saat ile 13:41:20'de (UTC 10:41:20) moment büyüklüğü (Mw) 7.2 olan bir deprem meydana gelmiştir. Çalışmada veri olarak depremden bir gün sonra Harita Genel Komutanlı̆̆ tarafindan hasar tespiti yapmak amacıyla alınan hava fotoğraflarından üretilen ortofotolar kullanılmıştır. Deprem sonrası görüntüde ilk olarak 2 farklı dokuda alan seçilmiştir. Hem homojen hem de heterojen alanların sinıflandırllmasında ilk adım olarak en uygun parametreler seçilerek segmentasyon işlemi gerçekleştirilmiştir. Segmentasyon aşamasında çoklu çözünürlük algoritmasından faydalanılmıştır. Yapılan farklı denemeler sonucunda en uygun şekil faktörü ve renk değerleri göz önüne alınmıştır. Bir sonraki aşamada, nesne tabanli sinıflandırmada kullanılan ve 'kontrollü' ve 'kontrolsüz' olarak adlandırılan iki farklı sınıflandırma yaklaşımı uygulanmış ve bu yöntemlerin sınıflandırma doğrulukları karşılaştırılmıştır.

\section{Anahtar Sözcükler}

Deprem, Yıkım Alanları, Nesne Tabanlı Sınıflandırma, Segmentasyon, Ortofoto

\section{Application of Object Based Image Classification Using Orthophotos: A Case Study of the Van-Erciş Earthquake}

\begin{abstract}
Earthquakes are the most destructive natural disasters, causing massive loss of life, infrastructure damages and serious financial losses. Earthquake-induced building damage detection is a very important step after earthquakes since such buildings pose a risk for cities. The recent advances in digital photogrammetry/remote sensing technology and satellite sensor/camera systems have inspired to emerge new and different research areas and applications. With the development of digital camera technology since 1950's, it has become possible to produce orthophotos with high spatial resolution and positional accuracy. These orthophotos are used successfully in the extraction of the details and the thematic classification. Depending on the high spatial image resolutions, the use of object-based approach has gained importance and has become widespread rather than the traditional pixel-based approach in the thematic classification. The town of Erciş in Van province, situated in the eastern part of Turkey, was selected for the study. In this region, an earthquake with moment magnitude (Mw) of 7.2 was occurred at 10:41 UTC (13:41 local time) on October 23th, 2011. In this study, the orthophotos produced from the aerial photographs taken one day after the earthquake by the General Command of Mapping for the purpose of damage detection. In the post-earthquake ortophotos, 2 different types of sites were selected as the study areas. As an initial step, segmentation process was carried out by selecting the most suitable parameters for the classification of both homogenous and heterogeneous areas. In the segmentation phase, the multi-resolution algorithm was utilized. After doing different trials, the most suitable shape factor and compactness values were considered. In the next step, two different classification approaches, namely "supervised" and "unsupervised", used within the object based image classification were applied and their classification accuracies were compared.
\end{abstract}

$\underline{\text { Keywords }}$

Earthquake, Debris Areas, Object Based Image Classification, Segmentation, Orthophoto

\footnotetext{
* Sorumlu Yazar: Tel: +90 (216) 5163310 Faks: +90 (216) 3320241

E-posta: asli.turgutalp@boun.edu.tr (Sabuncu A), fsunar@itu.edu.tr (Sunar F)
} 


\section{Giriş}

Afetler, toplumun sosyoekonomik faaliyetlerini önemli ölçüde aksatan, canlılara ve çevreye büyük zararlar veren, yaralanmalara, can ve mal kayıplarına neden olan büyük oranda veya tamamen insanların kontrolü dışında gerçekleşen doğal ve teknolojik olayların sonuçlarıdır. Afetler ister teknolojik kaynaklı, ister doğal kaynaklı olsun tarih boyunca insanlığın olduğu her yerde olmuştur ve olmaya devam edecektir. 1961-2010 yılları arasında CRED'in (Centre for Research on the Epidemiology of Disasters) yaptığ 1 araştırmanın sonuçlarına göre en fazla ölüme neden olan ilk 100 doğal ve teknolojik afet incelendiğinde can kaybının 60 milyonun üzerinde ve etkilenen insan sayısının 129 milyonun üzerinde olduğu görülmektedir. Ayrıca ekonomik kayıplar incelendiğinde ise aynı dönem ilk 100 doğal ve teknolojik afet için, yaklaşık 750 milyar dolarlık bir kayıp söz konusudur (Guha-Sapir vd. 2013).

Günümüzde uydu teknolojisinde gözlenen hızlı gelişmelerin etkisi yalnızca uydu görüntülerinde değil aynı zamanda hava fotoğraflarında da görülmektedir. Uydu algılayıcı ve dijital kamera sistemlerindeki bu önemli gelişmeler, farklı ve yeni araştırma konu ve uygulamalarının ortaya çıkmasına neden olmuştur. Teknolojik gelişmeler, yeryüzüne ait renkli görüntülerin elde edilmesi sürecinde dikkat çekecek ölçülerde; veri elde etme süresinin kısalmasını, maliyetin azalmasını ve yüksek mekânsal çözünürlüklere ulaşılmasını sağlamıştır. Zengin bilgi içeriğine sahip yüksek çözünürlüklü ortofotolar (havadan veya uydudan elde edilen), görsel olarak çok zengin bilgi içeriği nedeniyle birçok uzaktan algılama uygulamalarında sıklıkla kullanılmaktadır. Diğer bir ifade ile çok çeşitli haritaların üretilmesinde artan ihtiyaç doğrultusunda, yüksek çözünürlük ve doğruluğa sahip renkli hava/uydu görüntülerden elde edilen ortofotoların kullanımına yönelim hızla artmaya başlamıştır.

Ortofotoların ve uydu görüntülerinin mekansal çözünürlüğü, binaların tespitinde önemli rol oynamaktadır. Binaların tespiti ve çıkarımı elle ya da otomatik olmak üzere 2 farklı yöntemle yapılmaktadır. Otomatik çıkarım işlemi, elle çıkarım işlemine göre daha hızlıdır ve kullanıcılara zaman tasarrufu sağlamaktadır (Baltsavias vd. 2001). Farklı çatı tipleri ve renkleri (kiremit, sac, toprak vb. çatılar) ile farklı inşaat teknikleri kullanılarak yapılan binaların spektral özellikleri, farklı nesneler (asfalt, tarım alanı vb.) ile benzerlik gösterebilmektedir. Bu benzerlik, yanlış veya eksik bina tespitlerine neden olmaktadir.

$\mathrm{Bu}$ çalışmada, deprem sonrası hasar görmüş veya yıkılmış binaların tespitinde yüksek çözünürlüklü ortofotoların uzaktan algılamada kullanılabilirliği ve uygulamadaki sınırlamalar araştırılmıştır. Çalışma kapsamında, nesne tabanlı sınıflandırma ile yıkılmış binaların, çadır kentin ve enkaz alanlarının tespiti yapılmıştır. Uygulamada iki farklı sınıflandırma yaklaşımı olan kontrollü ve kontrolsüz sınıflandırma yüksek çözünürlüklü ortofotolara uygulanmış ve her iki yöntemin sınıflandırma başarısı doğruluk analizleri yapıldıktan sonra karşılaştırılmıştır.

\section{2. Çalışma Bölgesi ve Veri Seti}

Türkiye, depremler açısından dünyanın en aktif bölgelerinden biri olan Alp-Himalaya deprem kuşağı üzerinde yer almaktadır. Afrika ve Arap levhalarının Avrasya levhası ile çarpışması, Türkiye ve çevresinin tektoniğinin oluşumunda önemli bir role sahiptir. Anadolu levhası kuzeyde Kuzey Anadolu Fayı (KAF), güneyde Doğu Anadolu Fayı (DAF) ve batıda geniş bir açılma zonu ile çevrilmiştir. KAF ve DAF, doğuda Karlıova'da kesişmektedir (Allen 1969; McKenzie 1972; Dewey 1976; Toksoz vd. 1979; Jackson ve Mc Kenzie 1988; Sengor vd. 1985; Dewey vd. 1986; Barka 1997). Çalışma bölgesi olarak, Türkiye'nin doğusunda yer alan Van ili Erciş ilçesi seçilmiştir. Çalışma bölgesinin koordinatları 38 29' 57' Kuzey enlemi, 43² 20' 55', Doğu boylamıdır (Şekil 1) (Sabuncu vd. 2016).

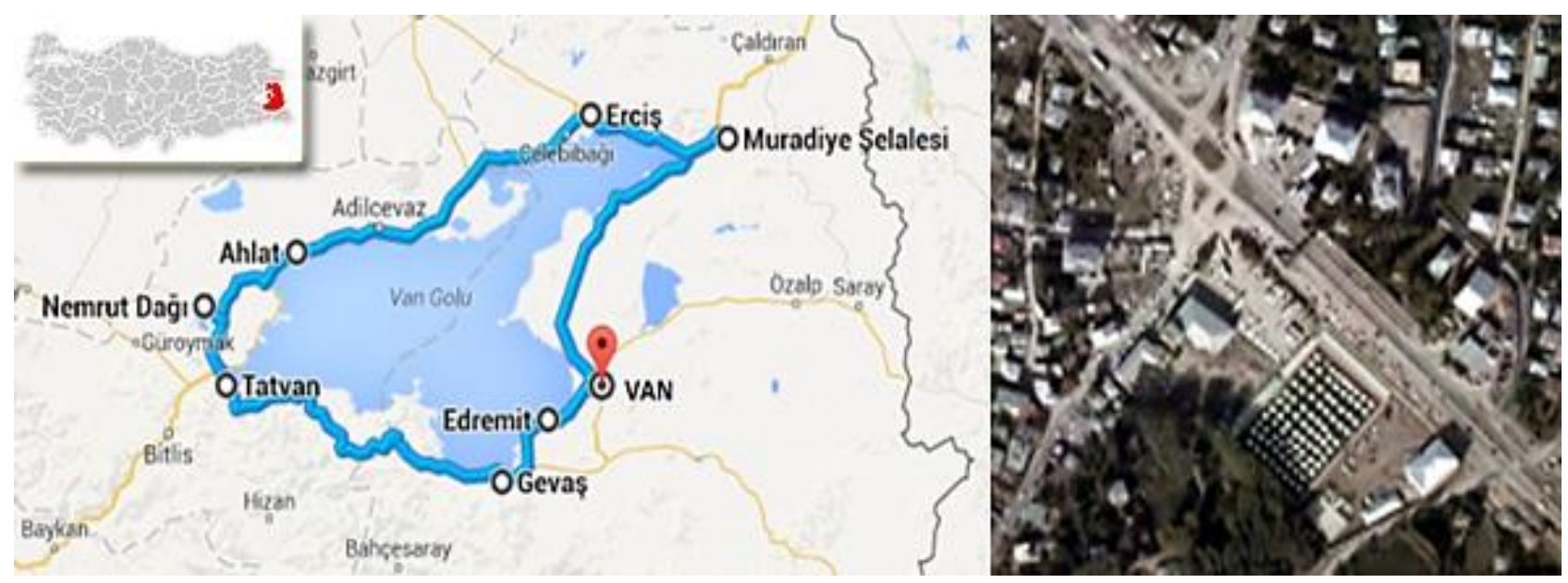

Şekil 1: Çalışma bölgesinin konumu ve ortofoto görüntüsü 
Van ve civarında da gerek aletsel dönemde kaydedilmiş, gerekse tarihsel kayıtlara girmiş hasar yapıcı depremlerin varlığ 1 bilinmektedir. 23 Ekim 2011 tarihinde yerel saat ile 13:41:20'de (UTC 10:41:20) moment büyüklüğ̈̈ 7.2 olan bir deprem meydana gelmiştir. Depremin merkez üssü Van şehir merkezinin $30 \mathrm{~km}$ kuzeyi olup Tabanlı köyüdür. Deprem yaklaşık $200 \mathrm{~km}$ yarıçapındaki bir bölgede hissedilmiştir. 50 saniye süren deprem $26 \mathrm{~km}$ derinlikte gerçekleşmiştir. Van-Erciş depremi Türkiye'de son 110 yıl içinde meydana gelen en büyük ve yıkıcı ilk 10 deprem içinde yer almaktadır (Erdik vd. 2012; Korkmaz 2015; Baran vd. 2014). Gerçekleştirilen çalışma kapsamında, Van ili Erciş ilçesini kapsayan 24 Ekim 2011 tarihli, Harita Genel Komutanlığı'ndan temin edilen yüksek çözünürlüklü ortofotolar kullanılmıştır. 1296 km²'lik afet bölgesinin yüksek çözünürlüklü ortofotolarının çözünürlüğ̈ $45 \mathrm{~cm}$ 'dir ve 3 spektral banta sahiptir. 152 adet hava fotoğrafı, Microsoft UltraCAM-X sayısal hava kamerası ile alınmıştır. Kameranın piksel boyutu $7.2 \mu$ m, odak uzaklığ 100 mm'dir.

\section{Nesne Tabanlı Sınıflandırma}

Uzaktan algılanmış görüntüler yardımıyla yeryüzü objelerine ilişkin bilgi çıkarımında en sık kullanılan yöntem görüntü sınıflandırmasıdır. Sınıflandırma işlemi, görüntü üzerindeki her bir piksele ait yansıma ve parlaklık değerleri kullanılarak piksellerin kullanıcı tarafından belirlenen sınıflara ayrılması işlemidir. Genel olarak sınıflandırma işleminde piksel tabanlı ve nesne tabanlı sınıflandırma yöntemleri kullanılmaktadır. Son yıllarda geleneksel piksel tabanlı sınıflandırma yöntemi yerine nesne tabanlı sınıflandırma yöntemi kullanılmaya başlanmıştır. Bunun en önemli nedeni olarak, uydu görüntü verilerinin ve hava fotoğraflarının son yıllarda mekansal çözünürlüklerinin artması ile mevcut olan zengin bilgi içeriklerinin piksel tabanlı yaklaşımdan elde edilen ürünlerde tam olarak yansıtılamaması olarak gösterilebilir (Navulur 2007). Ayrıca klasik piksel tabanlı sınıflandırmalarda, sadece pikselin gri değerine dayalı detay çıkarımı esastır. Yüksek çözünürlüklü veriler, zengin bilgi içeriği nedeni ile piksel tabanlı sınıflandırma sonuçlarında tutarsız sonuçlar verebilmektedir.

Nesne tabanlı sınıflandırma, geleneksel piksel ve alt-piksel tabanlı sınıflandırma işlemlerinin tam tersi bir yaklaşım olup, tekil pikseller ile değil görüntü üzerindeki benzer spektral özelliklere sahip piksellerin gruplandırılarak bu pikselleri temsil eden görüntü objelerinin oluşturulması ve pikseller yerine söz konusu objelerin sınıflandırılması temeline dayanmaktadır (Blaschke 2010; Myint vd. 2011). Bu işlem sayesinde görüntü üzerindeki milyonlarca piksel yerine bunları temsil eden objeler sınıflandırılmaktadır. Nesne tabanlı sınıflandırma yaklaşımında, yapı, doku, spektral bilgiler ve nesnelerin büyüklükleri sınıflandırma işleminde dikkate alınır ve çok sayıda ek bilgi görüntü nesnelerinden çıkartılabilir. Bunu sağlayan şekil, doku, komşuluk ve diğer obje tabakalarından gelen bilgilerdir.

\subsection{Segmentasyon}

Nesne tabanlı sınıflandırmada en önemli ve ilk aşama segmentasyon aşamasıdır. Segmentasyon, benzer spektral özelliklere sahip piksellerin gruplandırılması ve görüntü objelerinin oluşturulması işlemidir. Segmentasyonun amacı; görüntünün birbirinden farklı alt bölümlere ayrılması ve görüntüden anlamlı nesneler yaratılmasıdır (Baatz ve Schape 2000). Ayrıca, çoğu durumda belirli bir görev için bir görüntüde ilgilenilen, istenilen nesnelerin otomatik olarak çıkarılmasının mümkün olması da segmentasyonun amaçları arasındadır. Segmentasyon işlemi, yukarıdan-aşağıya (topdown) ve aşağıdan-yukarıya (bottom-up) olmak üzere iki farklı yöntem olarak işlemektedir (Definiens 2012). Yukarıdan aşağıya yönteminin temelinde bütünün en küçük parçalara ayrılması işlemi vardır. 3 farklı yukarıdan aşağıya segmentasyon metodu bulunmaktadır. Bunlar; satranç tahtası segmentasyon (chessboard segmentation), dörtlü ağaç tabanlı segmentasyon (quadtree-based segmentation) ve kontrast bölümlemesi segmentasyon (contrast split segmentation) algoritmalarıdır. Segmentasyon işleminin ikinci stratejisi aşağıdan yukarıya bölümlemedir. Bu yaklaşımda, küçük parçalar belirli bazı kriterler göz önüne alınarak büyük parçalar olarak elde edilmektedir. Aşağıdan yukarıya strateji için kullanılan en önemli yöntem "Çoklu Çözünürlüklü Segmentasyon (Multiresolution Segmentation)” yöntemidir (Baatz ve Schape 2000; Benz vd. 2004). Çoklu çözünürlüklü segmentasyon algoritması ile segmentasyonda ölçek, şekil ve yoğunluk olarak verilen 3 parametre kullanıcı tarafından belirlenir. Bu 3 parametre içinde en önemlisi ölçek parametresidir. Çoklu çözünürlüklü segmentasyon aşamasında, ölçek parametresi, renk/şekil parametresi ve yumuşaklık/yoğunluk parametreleri olabildiğince gerçeğe yakın belirlenmelidir. Renk/şekil ve yumuşaklık/yoğunluk parametreleri birbirini 1'e tamamlar.

\section{Uygulama}

Nesne tabanlı sınıflandırma işlemi sırasında analizleri daha kısa sürede gerçekleştirebilmek için iki farklı dokuda çalışma bölgesi seçilmiştir. Farklı 2 dokunun belirlenmesinde alanın heterojen ve homojen yapıda olması esas teşkil etmiştir. Heterojen bölgede birçok arazi örtüsü ve sınıfı yani çeşitli yapıda ve tipte binalar, yeşil alanlar, tarım alanları, boş alanlar, karışık alanlar, yıkılmış binalar (farklı yıkılma şekilleri gösteren binalar), enkazlar, yollar (asfalt, ana yol, tali yol), gölge alanlar göz önüne alınmıştır. Homojen dokudaki bölge, daha genel ve/veya daha az kompleks arazi örtüsü/sınıfını yani tek tip yapı tipi, geniş ormanlık alanlar, anayollar, gölge alanlar ve yıkılmış binaları içermektedir. 
Çalışmada ilk adım olarak, homojen ve heterojen dokudaki her 2 bölge için öncellikle segmentasyon algoritması uygulanmıştır. Segmentasyon algoritması için bu tipteki bölgeler için literatürdeki benzer çalışmalarda da sıklıkla uygulanan çoklu çözünürlüklü segmentasyon yaklaşımı kullanılmıştır (Şekil 2).

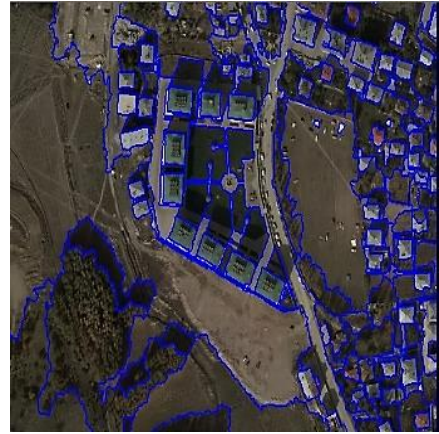

(a)

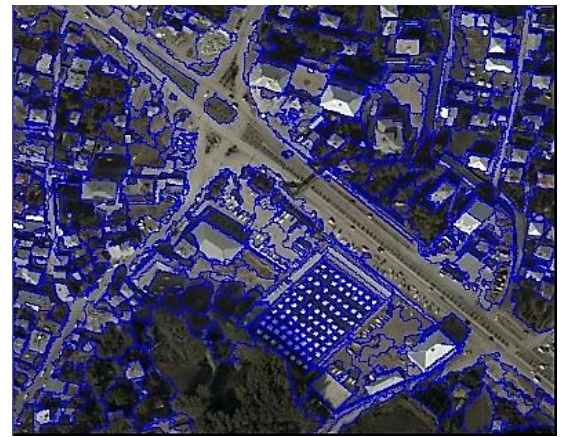

(b)

Şekil 2: Çoklu çözünürlüklü segmentasyon işlemi (a) homojen bölge - ortofoto (b) heterojen bölge - ortofoto

Çoklu çözünürlüklü segmentasyon adımında her bir bölge için göz önüne alınan parametreler Tablo 1'de verilmiştir. Çalışma kapsamında ortofotoların segmente edilmesi ve görüntü nesnelerine ilişkin özelliklerin tanımlanmasında e-Cognition yazılımından yararlanılmıştır.

Tablo 1: Homojen ve heterojen dokudaki çalışma bölgeleri için kullanılan segmentasyon parametre ve değerleri

\begin{tabular}{|c|c|c|c|c|c|}
\hline \multicolumn{7}{|c|}{ Kullanılan parametreler ve değerler } \\
\hline Çalışma Bölgesi & Ölçek & Renk & Şekil & Yumuşaklık & Yoğunluk \\
\hline Ortofoto - Homojen & 100 & 0.4 & 0.6 & 0.3 & 0.7 \\
\hline Ortofoto - Heterojen & 120 & 0.6 & 0.4 & 0.3 & 0.7 \\
\hline
\end{tabular}

\subsection{Kontrolsüz Sınıflandırma}

Kullanıcı müdahalesi olmadan görüntü üzerindeki piksellerin belirli algoritmalar kullanılarak otomatik olarak sınıflandırılması işlemi kontrolsüz sınıflandırma olarak tanımlanmaktadır. Literatürde kümeleme olarak bilinen bu işlem tam otomatik bir algoritma olup, görüntü verisinde mevcut olan doğal spektral gruplaşmaları/kümelenmeleri belirler. Çalışmada kontrolsüz sınıflandırma aşamasında ilk adım olarak sınıflar belirlenmiş, ardından her bir sınıf spektral özellik, doku ve şekil özelliklerinin bir veya birkaçının birleşimi ile tanımlanmıştır. Kullanılan sınıflar ve her iki farklı dokudaki bölge için kullanılan sınıf tanımlayıcı özellikleri Tablo 2'de verilmiştir.

Tablo 2: Her iki farklı çalışma bölgesi için sınıflar ve tanımlayıcı özellikleri

\begin{tabular}{|l|l|l|}
\hline Sınıflar & Homojen bölge - ortofoto & Heterojen bölge - ortofoto \\
\hline Tarım alanı & Aritmetik ortalama & - \\
\hline Yeşil alan (orman, çimenlik, bahçe) & Alan + Aritmetik ortalama & Alan + Alan \\
\hline Bina (özel ve kamu) & Dikdörtgensel uyum+Eliptik uyum & Dikdörtgensel uyum+Eliptik uyum \\
\hline Çadır kent & - & Alan+Şekil indeksi \\
\hline Yıkılmış binalar & İskeletteki geometrik özellikler & Parlaklık + İskeletteki geometrik özellikler \\
\hline Enkaz & - & Haralick doku analizi \\
\hline Açık alanlar & Sinıflandırılmamıs segmentler & Parlaklık \\
\hline Gölge & Parlaklık & Parlaklık \\
\hline Karışık alanlar & - & Sinıflandırılmamış segmentler \\
\hline Yol (asfalt, anayol, tali yol, kaldırım vb.) & Boy/En & Boy \\
\hline
\end{tabular}

Her iki bölge için yapılan kontrolsüz sınıflandırma sonucu elde edilen sınıflandırılmış görüntüler Şekil 3'te verilmiştir. Kontrolsüz sınıflandırma sonuçları incelendiğinde, homojen bölgede bölgenin dokusu nedeni ile çok fazla karışan sınıf olmamıştır, sadece bazı bölgelerde gölge sınıfı ile bina sınıfının karıştığı gözlenmiştir. Yıkılmış bina sınıfı uygun seçilen parametreler nedeniyle doğru sınıflandırılmıştır. 
Heterojen bölgede yapılan kontrolsüz sınıflandırma sonucunda bölgenin dokusu sebebi ile karışan sınıf sayısı daha fazladır. Özellikle karışık alanlar sınıfı ile enkaz sınıfının ayırt edilmesinde zorluklar yaşanmıştır.

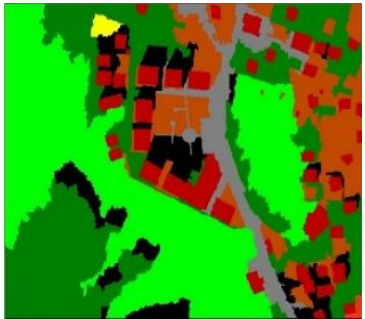

(a)

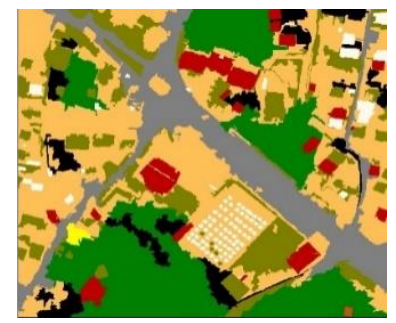

(b)
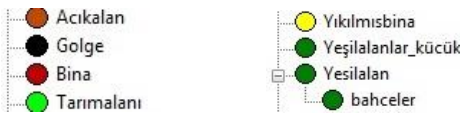

$O$ Enkaz
Karıskalan
Yol

Şekil 3: Kontrolsüz sınıflandırma sonucu (a) homojen bölge - ortofoto (b) heterojen bölge - ortofoto

\subsection{Kontrollü Sınıflandırma}

Kontrollü sınıflandırma yönteminde görüntüde hangi sınıfların göz önüne alınacağı ya da görüntüden hangi sınıfların elde edilmek istenildiği kullanıcı tarafindan önceden belirlenir. Bu bağlamda, görüntüde göz önüne alınacak sınıflara ait yardımcı veriler için kontrol alanları seçilir. Bu yardımcı veriler, arazi çalışmalarından, hava fotoğraflarının analizinden ve/veya konu ile ilgili mevcut haritalardan elde edilebilir (Mather 1987). Çalışmada ilk adım olarak göz önüne alınan sınıflar belirlenmiş ve her bir sınıf, o sınıfı temsil eden eğitim segmentleri ile tanımlanmıştır.

Görüntü işlemede kullanılan eğitim segmentleri ile kontrollü sınıflandırma sonucu çıktı görüntüleri sırasıyla Şekil 4 ve Şekil 5'de gösterilmektedir. Kontrollü sınıflandırma sonuçlarının kontrolsüz sınıflandırma sonuçlarına göre doğruluğunun daha fazla olduğu görülmüştür. Kontrollü sınıflandırma da seçilen eğitim sınıflarının optimum seçilmiş olması daha doğruluklu sınıflandırma sonucunun elde edilmesinde etkili olmuştur. Homojen bölgede bina sınıfı ile bazı tali yolların karışmış olduğu görülmektedir, bu ise her iki sınıfın spektral özelliklerinin birbirine çok yakın olmasından kaynaklanmaktadır. Heterojen bölgede doğruluk kontrolsüz sınıflandırmaya göre daha fazladır ancak yine de dokunun karışık olması sebebi ile çadır kentte yer alan bazı çadırlar ile binalar karışmıştır. Enkaz sınıfı birçok farklı materyalleri içerdiği için yol kenarlarındaki bazı boş alanlarla karışmıştır. Bu ise bazı yolların enkaz sınıfı olarak sınıflandırılmasına neden olmuştur.

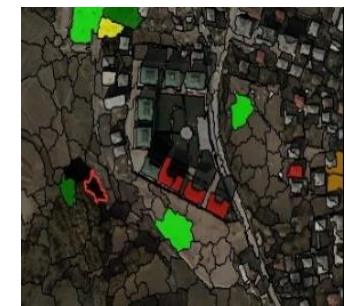

(a)

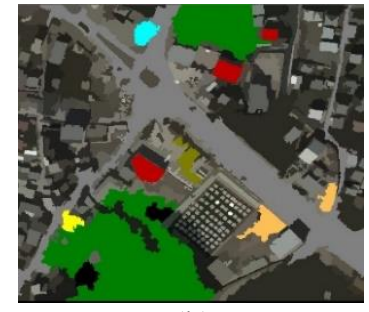

(b)

Şekil 4: Eğitim segmentleri (a) homojen bölge - ortofoto (b) heterojen bölge - ortofoto

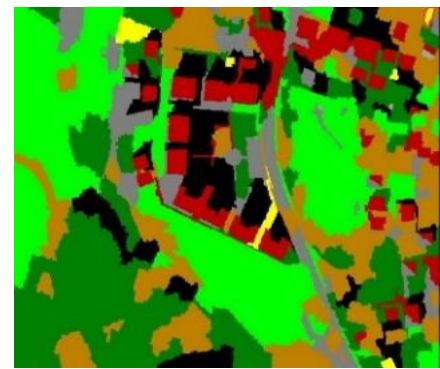

(a)

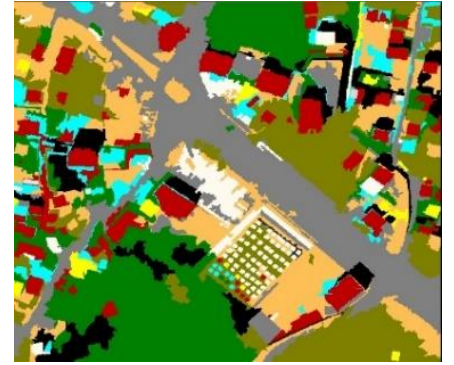

(b)

Yesilalan

$\bigcirc \mathrm{Yol}$

Şekil 5: Kontrollü sınıflandırma sonucu (a) homojen bölge - ortofoto (b) heterojen bölge - ortofoto 


\subsection{Doğruluk Analizi}

Sınıflandırma sonucu ile doğru olduğu kabul edilen coğrafi verinin karşılaştırma işlemi doğruluk analizi olarak adlandırılmaktadır. Doğruluk analizinde hata ne kadar küçükse, doğruluk o kadar yüksek olacaktır. Sınıflandırmayı değerlendirmek üzere yapılan doğruluk analizi için öncelikle kontrol segmentleri seçilmiştir. Ancak çadır kent ve enkaz alanı gibi bazı küçük sınıflar için tek bir örnek olduğundan, doğruluk analizinde bu sınıflara ait örnekler hem eğitim segmenti hem de kontrol segmenti olarak kullanılmıștır. Doğruluk analizinde, her bir sınıf doğruluğunun ortalama değeri olan "Genel Doğruluk (GD; yüzde olarak)" ile sınıflandırma doğruluğunu ağırlıklı olarak hesaplayan bir istatistiksel ölçüt olan "Kappa Katsayısı (KK)" kullanılmıştır. Kontrol segmentlerine bağlı olarak yapılan hata matrisi ile doğruluk analizinde, doğruluklar kontrolsüz sınıflandırma da homojen bölge için GD: \%81, KK: 0.77 ve heterojen bölge için GD: \%66, KK: 0.61; kontrollü sınıflandırmada homojen bölge için GD: \%92, KK: 0.90 ve heterojen bölge için GD: \%71, KK: 0.66 olarak elde edilmiştir. Homojen ve heterojen bölgeler için kontrolsüz ve kontrollü sınıflandırma sürecinde hesaplanan hata matrisleri sırası ile için Tablo 3, 4, 5 ve 6 gösterilmiştir.

Tablo 3: Homojen bölge için kontrolsüz sınıflandırma sonucu hesaplanan hata matrisi

\begin{tabular}{|c|c|c|c|c|c|c|c|}
\hline & $\begin{array}{c}\text { Yeşil } \\
\text { alan }\end{array}$ & Yol & Bina & $\begin{array}{c}\text { Tarım } \\
\text { alanı }\end{array}$ & $\begin{array}{c}\text { Yıkılmış } \\
\text { bina }\end{array}$ & Gölge & $\begin{array}{c}\text { Açık } \\
\text { alan }\end{array}$ \\
\hline YA & 3 & 0 & 0 & 0 & 0 & 0 & 0 \\
\hline Y & 0 & 1 & 0 & 0 & 0 & 0 & 0 \\
\hline B & 0 & 0 & 4 & 0 & 0 & 0 & 0 \\
\hline TA & 0 & 0 & 0 & 1 & 0 & 0 & 0 \\
\hline YB & 0 & 0 & 0 & 0 & 1 & 0 & 0 \\
\hline G & 0 & 0 & 0 & 0 & 0 & 3 & 0 \\
\hline AA & 0 & 0 & 0 & 0 & 0 & 0 & 2 \\
\hline \multicolumn{7}{|c|}{ Genel Doğruluk: \%81 Kappa: 0.77 } \\
\hline YA: Yeşil alan Y: Yol B: Bina TA: Tarım alanı YK: Yıkılmış bina G: Gölge AA: Açık alan \\
\hline
\end{tabular}

Tablo 4: Heterojen bölge için kontrolsüz sınıflandırma sonucu hesaplanan hata matrisi

\begin{tabular}{|c|c|c|c|c|c|c|c|c|c|}
\hline & Bina & Yol & Gölge & $\begin{array}{c}\text { Çadır } \\
\text { kent }\end{array}$ & $\begin{array}{c}\text { Yeşil } \\
\text { alan }\end{array}$ & $\begin{array}{c}\text { Açık } \\
\text { alan }\end{array}$ & $\begin{array}{c}\text { Karışık } \\
\text { alan }\end{array}$ & Enkaz & $\begin{array}{c}\text { Yıkılmış } \\
\text { bina }\end{array}$ \\
\hline B & 3 & 0 & 1 & 0 & 0 & 0 & 0 & 0 & 0 \\
\hline Y & 0 & 1 & 0 & 0 & 0 & 0 & 0 & 0 & 0 \\
\hline G & 0 & 0 & 1 & 0 & 0 & 0 & 0 & 0 & 0 \\
\hline ÇK & 1 & 0 & 0 & 3 & 0 & 0 & 0 & 0 & 0 \\
\hline YA & 0 & 0 & 0 & 0 & 2 & 0 & 0 & 0 & 0 \\
\hline AA & 0 & 0 & 0 & 0 & 0 & 1 & 2 & 0 & 0 \\
\hline KA & 0 & 0 & 0 & 0 & 0 & 1 & 2 & 1 & 0 \\
\hline E & 0 & 0 & 0 & 0 & 0 & 0 & 0 & 1 & 0 \\
\hline YB & 0 & 0 & 0 & 0 & 0 & 0 & 0 & 0 & 1 \\
\hline
\end{tabular}

Tablo 5: Homojen bölge için kontrollü sınıflandırma sonucu hesaplanan hata matrisi

\begin{tabular}{|c|c|c|c|c|c|c|c|}
\hline & $\begin{array}{c}\text { Açık } \\
\text { alan }\end{array}$ & Bina & Gölge & Yol & $\begin{array}{c}\text { Yeşil } \\
\text { alan }\end{array}$ & $\begin{array}{c}\text { Yıkılmış } \\
\text { bina }\end{array}$ & $\begin{array}{c}\text { Tarım } \\
\text { alanı }\end{array}$ \\
\hline AA & 1 & 0 & 0 & 0 & 0 & 0 & 0 \\
\hline B & 0 & 2 & 0 & 0 & 0 & 0 & 0 \\
\hline G & 0 & 0 & 2 & 0 & 0 & 0 & 0 \\
\hline Y & 0 & 0 & 0 & 3 & 0 & 0 & 0 \\
\hline YA & 0 & 0 & 0 & 0 & 2 & 0 & 0 \\
\hline YB & 0 & 0 & 0 & 0 & 0 & 1 & 0 \\
\hline TA & 0 & 0 & 0 & 0 & 0 & 0 & 0 \\
\hline \multicolumn{7}{|c|}{ Genel Doğruluk: \%92 Kappa: 0.90 } \\
\hline
\end{tabular}


Tablo 6: Heterojen bölge için kontrollü sınıflandırma sonucu hesaplanan hata matrisi

\begin{tabular}{|c|c|c|c|c|c|c|c|}
\hline & $\begin{array}{c}\text { Yeşil } \\
\text { alan }\end{array}$ & Yol & Bina & $\begin{array}{c}\text { Tarım } \\
\text { alanı }\end{array}$ & $\begin{array}{c}\text { Yıkılmış } \\
\text { bina }\end{array}$ & Gölge & $\begin{array}{c}\text { Açık } \\
\text { alan }\end{array}$ \\
\hline YA & 3 & 0 & 0 & 0 & 0 & 0 & 0 \\
\hline Y & 0 & 1 & 0 & 0 & 0 & 0 & 0 \\
\hline B & 0 & 0 & 4 & 0 & 0 & 0 & 0 \\
\hline TA & 0 & 0 & 0 & 1 & 0 & 0 & 0 \\
\hline YB & 0 & 0 & 0 & 0 & 1 & 0 & 0 \\
\hline G & 0 & 0 & 0 & 0 & 0 & 3 & 0 \\
\hline AA & 0 & 0 & 0 & 0 & 0 & 0 & 2 \\
\hline \multicolumn{7}{|l|}{ Genel Doğruluk: \%81 Kappa: 0.77 } \\
\hline
\end{tabular}

\section{Sonuç ve Öneriler}

Bu çalışmada deprem sonrası yıkılmış ve ağır hasar görmüş binaların tespitinin ortofoto görüntüleri ve uzaktan algılamada kullanılan görüntü işleme yöntemleri ile kullanılabilirliği irdelenmiştir. Bu amaç doğrultusunda ilk olarak Van-Erciş bölgesi test alanı olarak seçilmiş, depremden 1 gün sonra elde edilen yüksek çözünürlüklü ortofotolardan yıkılmış ve/veya ağır hasar görmüş binaların tespiti için nesne tabanlı sınıflandırma yaklaşımı uygulanmıştır. Çalışma bölgesinde seçilen 2 farklı dokudaki 2 ayrı bölge için toplamda 9 ana sınıf ile kontrollü ve kontrolsüz sınıflandırma uygulaması yapılmıştır. Uygulama sırasında bazı temel sorunlar ve sınırlamaların olduğu gözlenmiş ve bu sınırlamalar aşağıda sıralanmıştır:

- Gelişmekte olan ve az gelişmiş ülkelerde düzenli yerleşim planı ve mimarisi genellikle kullanılmamaktadır. Çalışma bölgesinin içinde yer alan Erciş ilçesinin düzenli bir yerleşim planının olmaması sınıflandırma sonucunu negatif etkilemiştir. Ayrıca farklı türdeki çatı tiplerinin (kiremit, beton, çelik, toprak, çinko sac vb.) kullanılması binaların tespiti için olumsuz bir etken olmuştur.

- Kentsel alan içerisindeki birçok arazi sınıfı benzer veya aynı spektral özelliklere sahip olabilmektedir. Örneğin çalışma bölgesinde beton yollar, beton kaldırımlar, enkaz, yıkılmış binalar ve beton çatı kaplamaları yüzünden sınıflandırma sonucunda bazı sınıfların karışmış olduğu görülmüştür. Bu ise, farklı arazi tiplerinin benzer şekil ve spektral yansımalara sahip olduğu bölgelerde segmentasyon ve sınıflandırma doğruluğunu azaltmıştır.

- Bina çıkarımında en sık karşılaşılan sorun sağlam bina sınıfı ile yıkılmış bina sınıfının spektral olarak benzer yansımaya sahip olması sonucu karışım göstermesidir. Bu sorun, kural setlerinde binaların dikdörtgensellik uyum ve eliptik uyum parametrelerinin kullanımı ile giderilmiştir.

- Seçilmiş olan test alanlarında karşılaşılan diğer bir sorun ise çadırkent ve enkaz alanı gibi bazı sınıflar için tek bir örnek olmasıdır. Bu durumda eğitim segmenti olarak kullanılan alan, doğruluk analizinde de kontrol segmenti olarak kullanılmıştır (Sabuncu vd. 2016a; Sabuncu vd. 2016b).

Ülkemizin \%93'ü deprem açısından riskli sayılan bölgelerden oluşmaktadır. Türkiye nüfusunun \%98'i deprem tehdidi altında yaşamakta, sanayi kuruluşlarının \%98'i deprem bölgelerinde yer almakta ve bu sayının \%73'ü de aktif fay zonlarında bulunmaktadır. Gerçekleştirilmiş olan bu çalışma kapsamında, afet sonrası ağır hasar almış ve/veya tamamıyla yıkılmış binaların tespiti ile bunların diğer sağlam binalardan ayırt edilebilmesi önemlidir. Bu amaçla kullanılan ve depremin ardından temin edilen ortofotoların önemli bir veri kaynağı olduğu gösterilmiştir. Bina hasar tahminine yönelik gerçekleştirilmiş olan bu çalışmada kullanılan ortofotoların alım tarihi sınıflandırma sonuçlarında etkili olmuştur. Heterojen bölgelerde elde edilen düşük sınıflandırma doğruluğunun arttırılmasına yönelik olarak, kullanılan ortofotoların benzer zamanda alınmış yüksek çözünürlüklü uydu verileri, yükseklik verisi, yersel gözlemler, vb. diğer veri setleri ile entegre edilmesi planlanmakta ve böylelikle karar verici mekanizmaların çalışmalarında altlık olacak daha güvenilir tematik haritaların üretilmesi hedeflenmektedir.

\section{Teşekkür}

$\mathrm{Bu}$ çalışmada kullanılan ortofoto verileri Harita Genel Komutanlığı'ndan doktora çalışmasında kullanılmak üzere öneri verilerek temin edilmiştir.

\section{Kaynaklar}

Allen C.R., (1969), Active faulting in northern Turkey, Division of Geological Sciences, Contribution no. 1577, California Institute of Technology, Pasadena, California, U.S.A.

Baatz M., Schape A., (2000), Multi resolution segmentation: an optimization approach for high quality multi scale image segmentation. Proceedings of Twelfth Angewandte Geographische Informations verarbeitung'in İçinde, (J. Strobl, T. Blaschke, G. Griesebner Ed.), Wichmann-Verlag, Heidelberg, ss.12-23. 
Baltsavias E.P., Grun A., Gool L.V., (2001), Automatic extraction of man-made objects from aerial and space images (III), A.A. Balkema Publishers, Lisse, Netherlands, 426ss.

Baran E., Mertol H.C., Gunes B., (2014), Damage in reinforced-concrete buildings during the 2011 Van, Turkey, Earthquakes, Journal of Performance of Constructed Facilities, 28(3), 466-479.

Barka A., (1997), Neotectonics of the Marmara region, Active tectonics of northwest Anatolia: The Marmara Poly-Project'in İçinde, (Schindler C., Pfister M., Ed.), vdf Hochschulverlag AG an der ETH Zurich, ss.55-87.

Benz U.C., Hofmann P., Willhauck G., Lingenfelder I., Heynen M., (2004), Multi-resolution object-oriented fuzzy analysis of remote sensing data for GIS- ready information, ISPRS Journal of Photogramemetry and Remote Sensing, 58 (3-4), 239-258.

Blaschke T., (2010), Object based image analysis for remote sensing, ISPRS Journal of Photogrammetry and Remote Sensing, 65 (1), 2-16.

Guha-Sapir D, Hoyois Ph., Below R., (2013), Annual Disaster Statistical Review 2012: The Numbers and Trends, Brussels: CRED; 2013, http://cred.be/sites/default/files/ADSR_2012.pdf, [Erişim 24 Kasim 2016].

Definiens (2012), Definiens Developer XD 2.0.4. Reference Book, Definiens AG, München, Germany, http://www.imperial.ac.uk/ media/imperial-college/medicine/facilities/film/Definiens-Developer-Reference-Book-XD-2.0.4.pdf, [Erişim 12 Mayıs 2015].

Dewey J.W., (1976), Seismicity of northern Anatolia, Seismological Society of America Bulletin, 66, 843-868.

Dewey J.F., Hempton M.R., Kidd W.S.F., Saroglu F., Sengor A.M.C., (1986), Shortening of continental lithosphere: the neotectonics of Eastern Anatolia-a young collision zone, Collision Tectonics'in İçinde, (Coward M.P. and Ries A.C., Ed.), Blackwell Scientific Publications, Oxford, ss.3-36.

Erdik M., Yaver K., Demircioglu M., Sesetyan K., (2012), 23 October 2011 Van (Turkey) earthquake, Natural Hazards, 64 (1), 651 665.

Jackson J., McKenzie D., (1988), The relationship between plate motions and seismic tremors, and the rates of active deformation in the Mediterranean and Middle East, Geophysical Journal, 93(1), 45-73.

Korkmaz S., (2015), Observations on the Van earthquake and structural failures. Journal of Performance of Constructed Facilities, 29(1), doi: http://dx.doi.org/10.1061/(ASCE)CF.1943-5509.0000456.

Mather P.M., (1987), Computer processing of remotely sensed images: an introduction, John Wiley \& Sons Ltd., 360ss.

Myint S.W., Gober P., Brazel A., Grossman-Clarke S., Weng Q.H., (2011), Per-pixel vs. object-based classification of urban land cover extraction using high spatial resolution imagery. Remote Sensing of Environment, 115 (5), 1145-1161.

McKenzie D., (1972), Active tectonics of the Mediterranean Region, Geophysical Journal International, 30(2), 109-185.

Navulur K., (2007), Multispectral Image Analysis Using the Object-Oriented Paradigm, CRC Press, Florida, U.S.A., 184ss.

Sabuncu A., Uca Avci Z.D, Sunar F., (2016a), Preliminary results of earthquake-induced building damage detection with object-based image classification, ISPRS 2016, 12-19 July, Prague, Chech Republic.

Sabuncu A., Uca Avci Z.D., Sunar F., (2016b), Yüksek çözünürlüklü uydu verisi ile nesne tabanlı sinıflandırma uygulamasında mevsimsel koşulların etkisi, 6. Uzaktan Algılama-CBS sempozyumu (UZAL-CBS 2016), 5-7 Ekim, Adana.

Sengor A.M.C., Gorur N., Saroglu F., (1985), Strike slip faulting and related basin formation in zones of tectonic escape: Turkey as a case study, Strike Slip Deformation, Basin Formation, and Sedimentation'ın İçinde, (Biddle K.T. and Christie-Blick N., Ed.), Society of Economic Paleontologists and Mineralogists, Vol. 37, ss.227-264,

Toksoz M.N., Shakal A.F., Michael A.J., (1979), Space-time migration of earthquakes along the North Anatolian fault zone and seismic gaps, Pure and Applied Geophysics, 117, 1258-1270. 